\title{
Harnessing Technology in Chemistry Education
}

\section{Michael K. Seery}

Dublin Institute of Technology, Ireland

\section{Corresponding author:}

Michael K. Seery, Dublin Institute of Technology, Kevin St, Dublin 8, Ireland

Email: michael.seery@dit.ie

\begin{abstract}
Using technology when teaching or to support learning is becoming more common place. This perspective discusses the use of technology in our teaching by considering it from the viewpoint of what we need to support our curricula, investigating how technology can help. Nine approaches that have become popular in recent years are outlined with particular emphasis on curriculum delivery problems that they could address, and some recent literature examples of where they have been used. The integration of technology argued for is considered under the umbrella of cognitive load theory, and arising out of this, an approach of how we might progress the use of technology in our teaching is suggested.

Keywords: e-learning, blended learning, cognitive load theory, pre-lecture activities, pre-lab activities, clickers, worked examples, simulations, wikis, discussion boards, screencasting, Peerwise, flipped lecture
\end{abstract}

\section{Introduction}

How and why do we use technology in our teaching? Institutional directives for urging inclusion of "e-learning" in our curricula have led many educators to post notes and/or resources on their institutionally hosted virtual learning environments. Others have blazed a trail using a wide variety of approaches to include technology in their teaching. Thus we have arrived at a situation in which a wide range of applications of technology is in use, accompanied by a considerable literature which, more often than not, argues in favour of a given technological approach. Hence, it can be a difficult 
area for an educator to isolate which particular technological innovation might prove useful to them in their own module.

The rationale behind this perspective is underpinned by two important studies. The first is a survey of US university physics lecturers on their use of "research based instructional strategies" in their teaching (Henderson et al. 2012). This examined lecturer awareness of strategies studied and disseminated in the literature which were considered to work well in a teaching setting. For example, one aspect was a focus on the use of clickers in physics. Henderson et al. (2012) found that most staff knew about clickers, and a significant proportion had tried them out, but that the number who kept up their usage plummeted after the first attempt. The main reasons for this were determined to be the fact that clickers did not live up to their promise and that their implementation was not straightforward as had been promised by whoever promoted it to the lecturer in the first place-it didn't do what it said on the tin. The same researchers found a similar situation in respect of clicker use with regard to chemical engineering lecturers (Prince et al. in press).

The second is a very valuable study of chemistry students' perceptions of their university education conducted by the HEA Physical Sciences Centre (Higher Education Academy 2008) on their perceptions of their university education. When asked about "e-learning", students reported that it was the least effective and least enjoyable teaching method. A similar result was derived from institutional use of virtual learning environments across several institutions in Ireland.

These studies indicate that many lecturers are willing to try and include "e-learning" in their teaching, but after trying once, opt not to do so again; and many students feel that e-learning is not an important or enjoyable part of their learning experience. The counter argument to the Luddites nodding smugly at this juncture is to say that these conclusions most likely arise out of a misunderstanding of what technology in chemistry education can actually deliver. We can take some comfort in the knowledge that technology has not yet been able to replace our central role as educators. However, there is potential for it to help us in our job. This perspective aims to address the questions of how and why we use technology in our teaching by considering a range of technological approaches used in the context of their applicability in the teaching of chemistry (or, indeed, of any discipline). Rather than taking a technology-centred approach such as "I want to podcast, where can I use it?", it asks how technology can be used in our teaching: "I have a large amount of feedback to give: how can technology help?"

\section{Cognitive Load Theory}

The use of technology in our teaching may be considered in the context of cognitive load theory (CLT) which describes how we acquire, process and retain new information. Proponents of CLT argue that its application in learning design results in more effective learning, and improved retention of information in the long term memory, so that such information can be recalled when required in a given context. The theory distinguishes three types of cognitive load (Sweller 2008, Ayres \& Paas 2009):

1. Intrinsic load, which is caused by the complexity of the material and depends on the learner's understanding (prior knowledge) of the subject.

2. Extraneous load, which depends on the quality or nature of the instructional materials. Poor materials or those that require a large amount of working memory to process will increase the load and leave little capacity for learning.

3. Germane load, which is the mental effort required for learning. Because of the limited capacity of the working memory, germane load (the extent of learning) is dependent on the extent of the extraneous load, and also on the material and expertise of the learner - the intrinsic load. An expert on a topic is able to draw on prior knowledge, and release working memory capacity for germane load processing.

The mechanism of information processing was summarised succinctly by Mayer for the purposes of multimedia learning. This is similar in many respects to the information processing model familiar to many science educators through the work of Alex Johnstone (Johnstone 1997, Johnstone et al. 1994). Mayer's model is shown in Figure 1 (Mayer 2005, Clarke \& Mayer 2008).

Information is presented to users in the form of words and pictures (there are other channels too, but these are the most pertinent to e-learning). The user senses these and some of this is processed in the working memory, which can hold and process only some information at any time. If this material can be related to existing prior knowledge, it is integrated with it, and effective learning occurs - the new experiences and information are stored in the long-term memory. In this work, CLT is used as a basis for integrating technology into chemistry education as outlined in the sections below.

\section{Using Technology in our Teaching}

This perspective does not aim to be a comprehensive analysis of all reports relevant to the topics listed. For those interested, individual reviews on several topics are highlighted throughout. Instead, a selection of 


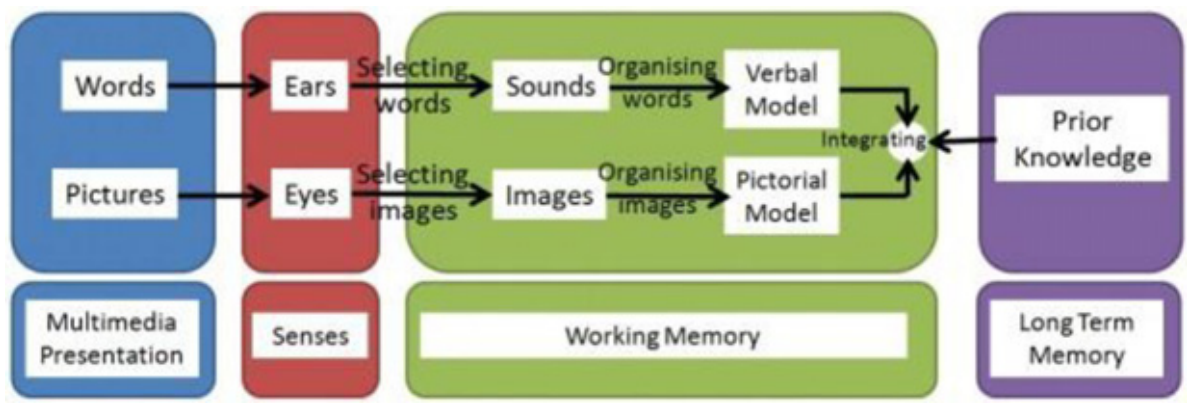

Figure 1 Cognitive Theory and Multimedia Learning (from Clarke \& Mayer 2008, Mayer 2005)

reports from well-grounded studies is used to indicate application of technology in particular settings. The target audience are those who are considering how technology might help in their teaching, but are perhaps overwhelmed by the variety of generally very positive, often technology-led reports available; as well as those who currently integrate technology into their teaching but wish to formalise the integration from a curriculum design perspective.

The terms "e-learning" and "blended learning" are so over-used that their definition is unclear. The main emphasis is on how we can include technology in our curriculum delivery so as to assist us in our lecture hall and laboratory teaching. The blending of online materials with in-class delivery is what is meant by blended learning in this context. The term "e-learning" is reserved for teaching that is predominantly or entirely online-for example an online module which students study at a distance from the university.
In considering our curriculum delivery in chemistry, our students mostly come to lectures, laboratories, and complete tutorials/workshops. Table 1 indicates some opportunities for incorporating technology into teaching to address common issues. These opportunities are the basis of the remainder of this article.

\section{Pre-Lecture Activities}

Chemistry lectures can present a significant amount of content with new information being represented in multiple ways (symbolic, molecular, macroscopic) (Johnstone 2000, Taber 2013). The amount of new information may overwhelm novice learners, so that they disengage or just consider the topics at a superficial level. In terms of cognitive load theory (CLT), described above, these situations impose a high intrinsic load on novice learners (those with little prior knowledge to call upon). A strategy to increase the capacity available for

Table 1 Opportunities for incorporating technology into teaching

\section{Curriculum delivery component causing a problem}

There is much new information to be delivered in lectures. No time in lecture to stop and discuss

Lecturer wishes to gauge whether students understand a topic in any given lecture

Students find basic problem solving strategies difficult

Group work difficult to mark/assess. Students complain that not everyone does their fair share

Students come unprepared to tutorials which end up being another lecture covering questions

Time required to develop innovative MCQs for online quizzes

Lecturer has much feedback to give, but common problems are apparent

\section{Example of technology that can be used to address problem}

Online pre-lecture/lab activities can present some or all of the material before a lecture allowing lecture time to be devoted to more in-depth discussion/interaction.

Clickers are widely used to examine student understandings at a given moment in a lecture.

Worked examples can allow students to learn how to approach problems of progressive difficulty. Simulations can be incorporated to allow students to test their own understanding.

Wikis (online document editing spaces) provide a means for all students in a group to work on a joint project. Each amendment is logged, so the traceability is very clear to all students and lecturer.

Discussion boards allow for tutorial questions to be discussed in advance, with more complex problems left to the tutorial.

Use student generated Peer Assessment on the PeerWise Platform.

Screencasts can be used to work through common problems found in assessments. 


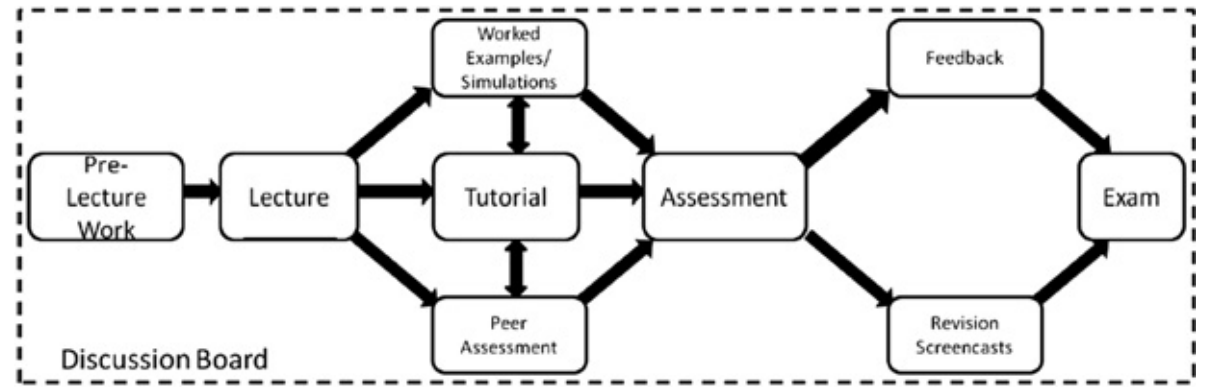

Figure $\mathbf{2}$ There are many ways to incorporate technology into supporting our teaching at various stages of curriculum delivery

germane load is to introduce some or all of the material in advance of lectures, and require students to complete some pre-lecture activities.

These activities can take the form of webpages, videos, or interactive tasks. Inclusion of quizzes or other interactive elements allows the student to gauge their understanding of a topic and enables inclusion of an assessment element that can be logged on the virtual learning environment (VLE). The latter element can be used as an incentive to encourage students to complete the activities prior to class. The concept of pre-lecture activities for chemistry in the context of cognitive load has been described by Sirhan et al. (1999), and the design of the e-resources and their inclusion into an introductory chemistry module is discussed by Seery \& Donnelly (2012). These studies determined that students' exam performance improved with the implementation of pre-lecture activities, a fact attributed to the reduced in-lecture cognitive load. The use of pre-lecture activities for both introducing and covering lecture topics is described in detail in Seery (2012).

\section{Pre-Laboratory Activities}

Pre-lab work is a much more familiar concept to chemists. By asking students to complete pre-lab exercises, we aim to help them better understand the theory underpinning a laboratory activity. It is, however, generally accepted that student learning in the laboratory is problematic (Hofstein \& Lunetta 2004, Bennett et al. 2009). As discussed for pre-lecture activities, laboratories can also impose significant cognitive overload on students as they are expected to understand the theory, perhaps use unfamiliar equipment, and follow a procedure. In this situation, a student may resort to simply coping with what they can process, and follow the list of instructions in their manual (Sweller 1988, Johnstone 1997a). Lecturers often report that students don't know what they are doing in the laboratory, and just "follow the procedure". While used more extensively than pre-lecture activities, pre-laboratory activities need some careful thought as to their purpose. A common strategy is to present information on how to complete a specific task: use an instrument, operate a vacuum line, etc. A study by Winberg \& Berg (2007) demonstrated that pre-lab activity was more valuable if it focused instead on non-numeric theory underpinning the laboratory. By avoiding a numeric activity, students were required to understand the conceptual basis of the lab, rather than completing a task-oriented exercise to get the right answer. In addition, their work purposefully avoided "how-to" components in their pre-lab work, as they felt that these were better delivered in the lab, as required (van Merrienboer et al. 2003). In terms of cognitive load theory, the strategy here was to allow students to develop a conceptual understanding of the laboratory activity, so that the intrinsic load was reduced in the lab class, allowing them to concentrate on the experimental aspects of the work.

\section{Clickers}

The use of personal response systems, or clickers, is a well-known strategy for aiming to engage students, especially in large lecture rooms. They have been much more embedded into physics instruction, probably due to the efforts of Eric Mazur and perhaps also to the nature of physics teaching at introductory level (Mazur 1997). Chemists have been slower to adopt clickers (MacArthur 2013). A perspective as recent as 2008 had difficulty finding reports of their use in chemistry lecture rooms (MacArthur \& Jones 2008), but the intervening years have seenan increase both in their use and in the types of activities in which they are used.

At their simplest, clickers can be employed to gauge class understanding of a concept by polling students via a multiple choice question, and numerous studies have reported this approach to be beneficial. An interesting example of this type is polling students to identify which they found to be the most difficult topic in a lecture (King 2008). 
The approach is not limited to first year students; Sevian \& Robinson (2011) argue that the use of clickers is feasible across all levels and sizes of chemistry classes. An additional element to simple polling is proposed by Wagner (2009). This involves asking students to predict an outcome and re-polling following a subsequent discussion. This approach probably best mirrors the "peer instruction" model proposed by Mazur for physics. Another aspect of simple polling is to use two-stage questioning such as that developed by Chandrasegaran et al. (2007) where students are asked to respond to a question, and then asked which reason best matches why they chose that particular answer. This approach is especially useful for identifying misconceptions. As technology has developed, so the boundaries of what clickers can be used for have been pushed back.

Both Ruder \& Straumanis (2009) and Flynn (2011) probe students' understandings of organic chemistry mechanisms using number sequence entry on clickers, whereby students have, for example, to enter in the sequence of events that occur in a given reaction mechanism. More recent work by Ryan (2013) describes the use of clickers in enabling peer debate and student-centred discussion in the context of how to address chemistry-specific learning outcomes; their use has also been found to enhance student retention (Gebru et al. 2012).

\section{Worked Examples}

Cognitive load theory is also the basis for incorporating worked examples into chemistry teaching. Even for simple algorithmic type problems, the solution involves applying a series of steps. Novice learners may not be capable of working through these steps, and so approach problem solving at a surface level - for example by memorising equations. When they are subsequently asked to address more open-ended problems, or problems based in a different context, they struggle to adapt. Worked examples provide a mechanism for learners to think through and complete the necessary steps to arrive at a solution (Mwangi \& Sweller 1998).

The target is that students familiarise themselves with an approach to solving problems. If a series of worked examples is provided to students, with each iteration removing one step in the process (called 'fading'), the student will eventually develop mastery in solving the problem in a step-wise manner, a process that can be easily facilitated by technology. Crippen \& Brooks (2009) provide a detailed overview of worked examples in chemistry in the context of cognitive theory.

Several instances of the use of worked examples are available. Crippen \& Earl (2007) describe the use of worked examples and self-explanation prompts in a web-based system to improve problem solving capacity in chemistry. The approach involves providing a weekly quiz to students that matches their lecture content, along with three related worked examples. The concept of fading was described by Behmke \& Atwood (2013). In this study, a series of worked examples was provided, with each one removing a step from the end of the process. The final iteration was the quiz question itself. The study showed that those students who were exposed to the fading approach out-performed those who were not provided with worked examples, as well asout-performing in subsequent tests. The authors conclude: "though there exists a large time commitment in producing CLT based homework problems, this study suggests that the reward, in terms of student performance, is well worth the investment."

\section{Simulations}

While worked examples can be used for more advanced problem solving, there may be several ways to approach a problem. The step-by-step approach may be over-simplistic, or even hinder students' own understanding (this is known in cognitive load theory as the expertise-reversal effect). Simulations offer an alternative to students working through a process so as to develop their own understanding of how it works or how to apply it to a different context. Simulations designed with cognitive load theory in mind allow students to develop their understanding of increasingly complex scenarios in a step-wise manner.

Rosenthal \& Sanger (2013) found that students who watched a simple animation followed by a more complex animation representing redox reactions were better able to explain what they had viewed in the more complex one, because of their prior exposure to the simplified one. This result has a wide applicability in the use of simulations in our teaching: providing students with simulations should be done with care so as to select iterations of appropriate complexity to introduce one or two key concepts with each iteration. Avramiotis \& Tsaparlis (2013) examined the effect of using simulations on problem solving ability. They noted that including simulations prior to a laboratory activity was an effective way to enhance problem solving ability. Furthermore, these types of simulation assisted students in guided inquiry exercises without the need for instructor facilitation (Moore et al. 2013).

\section{Wikis}

Wikis are online document editing spaces that can be made available to one person, a group of people, or open to the world. They can be as simple as one page, or can be a series of pages and sub-pages, with files and folders. Wikis are relatively 
new in the area of science education, but are increasingly being used in the workplace for document development. To date, reports of their use in education have mostly been restricted to teacher training (Shwartz \& Katchevitch 2013), although there have been some pilot studies on their use in several UK and Irish institutions (Seery \& Mc Donnell 2012).

The great advantage of wikis from a lecturer's perspective is traceability. With group work, a problem is often that individual contributions can be difficult to quantify, a situation that can lead to friction between group members, if it is perceived by students that other group members are not doing their fair share (Jacques 2000). Using a wiki, each contribution or amendment to the finished document is logged, so both students and lecturers can see who added what, and when. In recent pilot studies involving eight universities across the UK and Ireland, wikis were used as part of a context and problem-based learning module (Seery \& Mc Donnell 2012). Some conclusions drawn from this study were that participating lecturers found that wikis were a useful tool for organising group work and providing on-going feedback as students logged their work on the wiki, but that technical support was required initially (perhaps from institutional learning technologists) in setting up the wiki. Students in the pilot study overwhelmingly preferred using wikis to a paper based system, although there was some reluctance to edit other group members' work. This is an issue that needs to be discussed at induction stage, and it is an important aspect of genuine collaborative (as opposed to cooperative) group work. A guide to using wikis with some examples of feedback comments, suggestions for structuring wikis for group work, and prompts for student activity is available as part of the resources from the pilot (Royal Society of Chemistry 2012). Wikis are available in most virtual learning environments; the website www.pbworks.com provides a free platform for educational use.

\section{Discussion Boards}

Discussion boards are similar to wikis in that they are interactive online spaces. Their structure is similar to a noticeboard, on which someone posts a note, and other people post up replies. Despite their prevalence in all virtual learning environments, their usage usually remains restricted to supporting modules that are delivered entirely online (Dori \& Barak 2003, Seery 2012a). There are several reports on the use of discussion boards in chemistry education in a blended learning context. As early as 1999, Paulisse \& Polik described their use of discussion boards to supplement classroom material. For introductory classes, they used these as a distribution point for course materials, a place to discuss homework topics and the sharing of results of in-class activities. For advanced classes, they used the boards for activities such as student based discussions on homework topics, student created homework keys and sharing of laboratory data (Paulisse \& Polik 1999). One advantage the authors found was that time spent in answering queries on the discussion board was easily offset in dealing with individual student queries in person or by email, and often encouraged questions from students who would not ask questions in person.

A common issue with the concept of including discussion boards to support in-class teaching is that students are initially reluctant to use them. Markwell (2005) reports on lessons he learned from the use of discussion boards over six years in an undergraduate biochemistry course. These include: (i) timely responses and feedback to questions posed; (ii) creating an environment where students feel comfortable (including allowing anonymous posting); (iii) setting an example by posting sample queries and responses; and (iv) setting etiquette boundaries early on as required, including personal professionalism. An important point noted by Markwell is that "lurking" - viewing a discussion board without posting - is also an effective way for students to learn. The ability of students to focus on one particular task or topic at a time on the discussion board also resonates with effective application of technology in the context of cognitive load theory. Methods for moderating discussion boards are discussed in detail by Salmon (2004) and some useful concepts for considering the quality of moderator interactions are outlined by Angeli et al. (2003).

\section{Screencasting}

A screencast is an audio-visual presentation of lecture notes and/or lecturer made available online. Of all education technologies, it has seen a large uptake with lecturers commonly uploading videos to their own virtual learning environment, YouTube, and iTunesU. The use of videos in chemistry education can be traced back to 1957 (Blonder et al. 2013). Such is the extent of the use of screencasting, it is useful to discuss the different approaches taken. In a review of podcasting (audio only files), McGarr categorised podcasts into one of three categories: substitutional, supplemental, and student generated; the first two categories are used here (McGarr 2009). Substitutional screencasts are those which replicate the lecture experience-for example a lecture capture. These offer students the opportunity to revisit a lecture or catch up on a missed lecture. In that sense they are popular with students, but anecdotal evidence 
tends to show that they are used to revisit particular topics of difficulty within a lecture. Supplemental screencasts are those that capitalise on this. They are bespoke videos made to cover a particular topic that students may find difficult, or may be needed to prepare for a forthcoming topic. They can include quizzes or interactivity which can link into the VLE gradebook, both to provide immediate feedback and the motivation of assessment. Several examples of these developed as part of an HEA project are available at the website www.chemistryvignettes.com. A full description of the development of screencasts for chemistry educators is outlined by Read \& Lancaster (2012). An approach to structuring substitutional and supplemental podcasts, and by extension screencasts, for chemistry educators is also available (Seery 2012b).

As well as providing short summaries of topics, screencasting has also been shown to be an effective way to provide feedback on student work. Haxton \& McGarvey describe their use of tablet computers to annotate student work, recording their audio as they do so. The student receives a video file for feedback, which is a presentation of the lecturer going through their assignment and making comments and suggestions (Haxton \& McGarvey 2011).

\section{Student Generated Assessment}

One issue that arises in the development of online quizzes is the time required to develop suitable questions for a given topic. Textbook questions from the large publishing houses are now routinely available on answer websites (e.g. Yahoo Answers), so after a quick search, students will easily be able to find the answer to these questions. An emerging approach is to allow students to develop questions themselves, and a platform to enable this is Peerwise, a freely available online tool (http://peerwise.cs.auckland.ac.nz/). This approach allows students to develop and upload their own multiple choice questions and comment on and rate questions uploaded by their peers. A full description of how to guide students through the process of developing and evaluating questions is available, along with a worksheet for use in an introductory session (Bates \& Galloway 2013).

Recent reports on Peerwise are available for biochemistry (Bottomley \& Denny 2011) and organic chemistry (Ryan 2013). In both cases, the authors found that students participated eagerly, producing high quality questions. Students took responsibility for their own progress, using the platform to engage with peers to create questions with which they were having difficulty. All authors consider that the skills involved in developing questions and evaluating the questions of others promote higher order thinking skills.

\section{Integrating Technology into Curriculum Design}

Armed with a list of resources on how to include technology in teaching, the next stage is to consider what to use and, more importantly, why to use it. Unfortunately this is not a straightforward task. The lecturer needs to wear many hats: technological knowledge to develop the resources; pedagogic knowledge to appreciate how it fits into curriculum delivery; and content knowledge to actually develop the material (Blonder et al. 2013). An approach for lecturers can be to ask the question: what problem or issue do I want a chosen technology intervention to achieve? In answering this, they will address the content they wish to deliver (content knowledge), the problems or limitations with the current mode of delivery, how an alternative might help students learn more effectively (pedagogic knowledge) and what technology they need to use or develop to deliver this intervention (technological knowledge). This reasoning also leads to the developed resource having a sense of value in the curriculum delivery: it is there for a specific pre-determined purpose, and therefore is valued by the lecturer, and likely to be promoted in a way that will demonstrate its importance to students. Contrast this with a too common scenario whereby a statement such as "the notes are on the VLE" is made as an aside in a lecture. This simply places the notes in a location, with little indication as to why or how students should engage with them. Adding value to a resource by genuinely blending it into lecture delivery will mean that what students are meant to do with a resource, and how it fits into their learning in a module, will be clearer to all.

The "flipped lecture" is an emerging trend that is proving popular. The essential concept is that what takes place in the lecture and what takes place outside the lecture are flipped or inverted. Students watch the lecture prior to class time, and complete problem solving and discussion in the lecture time. Grounded in cognitive load theory, it harnesses many aspects of the technological innovations discussed above. It presents material before a lecture, so that students can go through this in their own time at their own pace. The time in the lecture hall is then dedicated to working through problems and developing an understanding of the topic.

Perhaps the attractiveness of the "flipped" model is that it provides a template for how we can use an array of technologies in our teaching, scheduling when we provide different technical supports. It can be a useful exercise to consider the delivery of a module component and sketch in what resources you think are required to support it. An example 
is shown, to illustrate the concept. This is merely to suggest what resources could be included at different points in the delivery; it is unlikely that any one module component would use all of these resources at one time!

\section{Conclusion}

This perspective opened by citing reports that suggest lecturers and students are under-whelmed by the use of e-learning in the teaching of chemistry. It is proposed that to enhance the effectiveness of technological interventions, we must individually decide in our own modules what problems or issues we wish to overcome, and how we intend to harness technology to address the delivery of content so that it will be of value to all concerned. The time taken to develop these resources should not be underestimated, but with careful thought about how they will support in-lecture teaching, it is more likely that they will be effective, reusable resources that the lecturer can use for many years to come.

\section{References}

Angeli, C., Valanides, N. and Bonk, C.J. (2003) Communication in a web-based conferencing system: the quality of computer-mediated interactions. British Journal of Educational Technology 34 (1), 31-43.

Avramiotis, S. and Tsaparlis, G. (2013) Using computer simulations in chemistry problem solving. Chemistry Education Research and Practice. doi: 10.1039/C3RP20167H.

Ayres, P. and Paas, F. (2009) Interdisciplinary perspectives inspiring a new generation of cognitive load research. Educational Psychology Review 21, 1-9.

Bates, S. and Galloway, R. (2013) Student-generated assessment. Education in Chemistry 50 (1), 18-21.

Behmke, D.A. and Atwood, C.H. (2013) Implementation and assessment of Cognitive Load Theory (CLT) based questions in an electronic homework and testing system. Chemistry Education Research and Practice. doi: 10.1039/C3RP20153H.

Bennett, S.W., Seery, M.K. and Sovegjarto-Wigbers, D. (2009) Practical Work in Higher Level Chemistry Education. In Innovative Methods in Teaching and Learning Chemistry in Higher Education (eds. I. Eilks and B. Byers). London: RSC.

Blonder, R., Jonatan, M., Bar-Dov, Z., Benny, N., Rap, S. and Sakhnini, S. (2013) Can You Tube it? Providing chemistry teachers with technological tools and enhancing their self-efficacy beliefs. Chemistry

Education Research and Practice. doi: 10.1039/C3RP00001J.

Bottomley, S. and Denny, P. (2011) A participatory learning approach to biochemistry using student authored and evaluated multiple-choice questions. Biochemistry and Molecular Biology Education 39 (5), 352-361.
Chandrasegaran, A.L., Treagust, D.F. and Mocerino, M. (2007) The development of a two-tier multiple-choice diagnostic instrument for evaluating secondary school students' ability to describe and explain chemical reactions using multiple levels of representation. Chemistry Education Research and Practice 8 (3), 293-307.

Clarke, R.C. and Mayer, R.E. (2008) E-Learning and the Science of Instruction, 2nd ed. San Francisco: Pfeiffer (Wiley).

Crippen, K.J. and Brooks, D.W. (2009) Applying cognitive theory to chemistry instruction: the case for worked examples. Chemistry Education Research and Practice 10 (1), 35-41.

Crippen, K.J. and Earl, B.L. (2007) Impact of web-based worked examples and self-explanation on performance, problem-solving, and self-efficacy. Computers and Education 49, 809-821.

Dori, Y.J. And Barak, M. (2003) A web-based chemistry course as a means to foster freshman learning. Journal of Chemical Education 80 (9), 1084-1092.

Flynn, A.B. (2011) Developing Problem-Solving Skills through Retrosynthetic Analysis and Clickers in Organic Chemistry. Journal of Chemical Education $\mathbf{8 8}$ (11), 1496-1500.

Gebru, M.T., Phelps, A.J. and Wulfsberg, G. (2012) Effect of clickers versus online homework on students' long-term retention of general chemistry course material. Chemistry Education Research and Practice 13 (3), 325-329.

Haxton, K.J. and McGarvey, D.J. (2011) Screencasting as a means of providing timely, general feedback on assessment. New Directions 7, 18-21.

Henderson, C., Dancy, M. and Niewiadomska-Bugaj, M. (2012) The Use of Research-Based Instructional Strategies in Introductory Physics: Where do Faculty Leave the Innovation-Decision Process? Physical 
Review Special Topics - Physics Education Research 8 (2), 020104.

Higher Education Academy (2008) Review of the Student Learning Experience. In Chemistry. HEA Physical Sciences Centre, Hull.

Hofstein, A. and Lunetta, V.N. (2004) The laboratory in science education: Foundations for the twenty-first century. Science Education 88 (1), 28-54.

Jacques, David (2000) Learning in Groups, p29. London: Kogan Page.

Johnstone, A.H., Sleet, R.J. and Vianna, J.F. (1994) An information processing model of learning: Its application to an undergraduate laboratory course in chemistry. Studies in Higher Education 19 (1), 77-87.

Johnstone, A.H. (1997a) '... And some fell on good ground'. University Chemical Education 1, 8-13.

Johnstone, A.H. (1997b) Chemistry teaching - Science or alchemy? Journal of Chemical Education 74, 262-268.

Johnstone, A.H. (2000) Teaching of chemistry - logical or psychological? Chemistry Education Research and Practice in Europe 1 (1), 9-15.

King, D.B. (2008) Using Clickers To Identify the Muddiest Points in Large Chemistry Classes. Journal of Chemical Education 88 (11), 1485-1488.

MacArthur, J.R. and Jones, L.L. (2008) A review of literature reports of clickers applicable to college chemistry classrooms. Chemistry Education Research and Practice 9, 187-195.

MacArthur, J.R. (2013) How Will Classroom Response Systems "Cross the Chasm"? Journal of Chemical Education 90 (3), 273-275.

Markwell, J. (2005) Using the discussion board in the undergraduate biochemistry classroom. Biochemistry and Molecular Biology Education 33 (4), 260-264.

Mayer, R.E. (2005) Cognitive theory of multimedia learning. In Cambridge Handbook of Multimedia Learning. Cambridge University Press.

Mazur, E. (1997) Peer Instruction: A user's manual. Upper Saddle River: Prentice Hall.

McGarr, O. (2009) A review of podcasting in higher education: Its influence on the traditional lecture. Australasian Journal of Educational Technology 25 (3), 309-321.

Moore, E.B., Herzog, T.A. and Perkins, K.K. (2013) Interactive simulations as implicit support for guided-inquiry. Chemistry Education Research and Practice, 2013. doi: 10.1039/C3RP20157K.

Paulisse, K.W. and Polik, W.F. (1999) Use of WWW discussion boards in chemistry education. Journal of Chemical Education 76 (5), 704-707.
Prince, M., Borrego, M., Henderson, C., Cutler, S. and Froyd, J. (in press) Use of Research-Based Instructional Strategies in Core Chemical Engineering Courses. Chemical Engineering Education.

Read, D. and Lancaster, S. (2012) Unlocking video: 24/7 learning for the iPod generation. Education in Chemistry 49 (4), 13-16.

Rosenthal, D.P. and Sanger, M.J. (2013) How does viewing one computer animation affect students' interpretations of another animation depicting the same oxidation-reduction reaction? Chemistry Education Research and Practice, 2013. doi: 10.1039/C3RP00006K.

Royal Society of Chemistry (2012) http://www.rsc. org/learn-chemistry/resource/res00000932/fastergreener-chemistry.

Ruder, A.R. and Straumanis, S.M. (2009) A Method for Writing Open-Ended Curved Arrow Notation Questions for Multiple-Choice Exams and ElectronicResponse Systems. Journal of Chemical Education 86 (12), 1392-1396.

Ryan, B.J. (2013) Line up, line up: using technology to align and enhance peer learning and assessment in a student centred foundation organic chemistry module. Chemistry Education Research and Practice, 2013. doi: $10.1039 / C 3 R P 20178 C$.

Salmon, G. (2004) E-Moderating, The Key to Teaching and Learning Online, 2nd ed. London: Kogan Press.

Shwartz, Y. and Katchevitch, D. (2013) Using wiki to create a learning community for chemistry teacher leaders. Chemistry Education Research and Practice. doi: 10.1039/C3RP20180E.

Seery, M. (2012a) Jump-starting lectures. Education in Chemistry 49 (5), 22-25.

Seery, M.K. (2012b) Moving an in-class module online: a case study for chemistry. Chemistry Education Research and Practice 13 (1), 39-46.

Seery, M. (2012c) Podcasting: support and enrich chemistry education. Education in Chemistry 49 (2), 19-22.

Seery, M.K. and Donnelly, R. (2012) The implementation of pre-lecture resources to reduce in-class cognitive load: A case study for higher education chemistry. British Journal of Educational Technology 43 (4), 667-677.

Seery, M.K. and Mc Donnell, C. (2012) Designing and Evaluating Context and Problem Based Learning Resources, presented to the Biennial Conference in Chemical Education, Pennsylvania State.

Sevian, H. and Robinson, W.E. (2011) Clickers promote learning in all kinds of classes_-small and large, graduate and undergraduate, lecture and lab. Journal of College Science Teaching 40, 14-18. 
Sirhan, G., Gray, C., Johnstone, A.H. and Reid, N. (1999) Preparing the mind of the learner. University Chemical Education 3 (2), 43-47.

Sweller, J. (1988) Cognitive Load During Problem Solving: Effects on Learning. Cognitive Science 12, 257-285.

Sweller, J. (2008) Human Cognitive Architecture. In Handbook of research on educational communications and technology (eds. J.M. Spector, M.D. Merrill, J. van Merrienboer and M.P. Driscoll), 3rd ed. New York: Routledge.

Taber, K.S. (2013) Revisiting the chemistry triplet: drawing upon the nature of chemical knowledge and the psychology of learning to inform chemistry education. Chemistry Education Research and Practice 14, 156-168.

van Merrienboer, J.J.G., Kirschner, P.A. and Kester, L. (2003) Taking the Load Off a Learner's Mind: Instructional Design for Complex Learning. Educational Psychologist 38 (1), 5-13.

Wagner, B.D. (2009) A Variation on the Use of Interactive Anonymous Quizzes in the Chemistry Classroom. Journal of Chemical Education 86 (11), 1300-1303.

Winberg, T.M. and Berg, C.A.R. (2007) Students' Cognitive Focus During a Chemistry Laboratory Exercise: Effect of a Computer-Simulated Prelab. Journal of Research in Science Teaching 44, 1108-1133. 